\title{
INFLUENCIA ESPAÑOLA EN LA ENFERMERÍA COLOMBIANA*
}

Ana Luisa Velandia M. **

La autora establece cuatro herencias recibidas por la enfermería colombiana: la tradición de tipo religioso, la condición femenina o de género, la herencia militar y la herencia antropológica o étnica. En esta última se tiene en cuenta tanto la herencia indígena como la influencia de la enfermería española, con todos sus influjos mediterráneos. La influencia religiosa se inicia con el sacerdote Jesuita Pedro Claver hacia 1610 -1617; continúa con los Hermanos Hospitalarios de San Juan de Dios hacia 1768 y posteriormente en 1873 con la llegada de las Hermanas de la Caridad de la Presentación. Compara la organización de la enfermería en el Hospital de la Santa Cruz de Barcelona, donde parece ser se empezó a organizar la enfermería como tal, analizando las funciones del Administrador de la sala de enfermos, el Servidor, las mujeres encargadas de las salas de enfermas o de niños, la Ecónoma, la Jefe de Sala, y el Enfermero Mayor, en relación con los cargos y funciones actuales en los Hospitales colombianos.

Larissa Lomnitz, citada por Martines Benitez ${ }^{15}$, considera que los elementos principales de la identidad profesional son de dos clases: los primeros, son residuales recogidos de la tradición histórica, que puede ser milenaria; y los segundos, son contemporáneos o añadidos en épocas más recientes.

Adaptando estos planteamientos al caso de la profesión de enfermería en nuestro país, yo he Llamado al conjunto de estos elementos Residuales: - "Herencias recibidas por tradición"; y a los elementos Añadidos, los he asimilado al - "Contexto socioeconómico, político y cultural del país en el Siglo XX.

En cuanto a las "Herencias recibidas por tradición", a mi modo de ver, en Colombia

\footnotetext{
*Conferencia dictada dentro de la programación de la Semana Universitaria conmemorativa de los 125 años de la Universidad Nacional de Colombia. Santafé de Bogotá. Septiembre 23 de 1992.

**Profesora Asociada. Facultad de Enfermería. Universidad Nacional de Colombia.
} 
estas herencias tienen que ver ante todo con: a) la tradición de tipo religioso, b) la relación de la enfermería con la condición femenina o de género, c) la herencia militar, y d) la herencia antropológica o etnica ${ }^{21}$.

La tradición religiosa es muy antigua y muy acentuada, y no es solamente visible en Colombia, es mundial. Incluso para algunos, la enfermería solamente nació como profesión cuando enfermeras seglares tituladas fueron ocupando los puestos que la disminución de las congregaciones religiosas iban dejando vacíos.

Esta influencia religiosa, condiciona también "10 femenino" a través del paradigma de mujer centrado en la figura de Maria Madre: un ser sumiso, pasivo, cuya meta se cifró en la espera silenciosa.

Para enfermería eso significa que sus valores fueron muy marcados por los valores religiosos y específicamente de la religión cristiana, desde donde la enfermería se ve como "servicio al prójimo", "vocación personal", "mística", en fin, más como "caridad", que como derecho ciudadano.

Influye también en los uniformes, ya que si "el hábito hace al monje", una enfermera sin su uniforme no es enfermera. y de paso, los uniformes de las enfermeras se parecían mucho a los hábitos de las monjas.

Así mismo se refleja en una serie de elementos, muy unidos al concepto de obediencia.

Incide en los horarios de trabajo, que se parecen más a los de las religiosas, que a los de los trabajadores en general.

Tiene que ver también con los salarios, que las religiosas no devengaban y las instituciones por 10 tanto no estaban acostumbradas a pagar.

Como ya se puede ver, la herencia remedida es muy profunda. Verdaderamente, hay mucho que hablar sobre la relación mujer-enfermera, y ella está representada en las llamadas "profesiones femeninas", es decir, aquellas ocupaciones que forman a la mujer, no solo para actuar como trabajadoras, sino que además le ayudan a su función considerada como primordial, la de ser madre; y unido a esto, esposa, hija, hermana, etc.

En realidad, la "cuestión femenina", está muy ligada a "10 religioso", al prototipo de la figura femenina: la Virgen Maria para las solteras y la Madre Dolorosa para las casadas. La primera, inocente y obediente: la segunda, sufrida y prudente. De allí se desprende que las características femeninas tengan tanta relación con las virtudes que se esperan de una monja: sumisión, bondad, ternura, suavidad, sutileza, etc.

Además, las religiosas al asumir la profesión de enfermería han reforzado estos valores, propios de las órdenes religiosas femeninas.

Por otra parte, la formación de la mujer hasta las primeras décadas del Siglo XX, era básicamente intrafamiliar y estaba orientada a formarla en los oficios de la casa, o dicho de una manera mas eufemística, a las actividades como "ama de casa".

La profesión de enfermería fue la primera que las mujeres colombianas pudieron estudiar en la Universidad. Aún cuando la profesión de maestra es más antigua; sin embargo 
como carrera universitaria, 10 es la enfermería.

La profesión de enfermera se convierte entonces, en una manera de legalizar, de formalizar, de "elegantizar" si se quiere, una educación femenina tradicional, tendiendo a atender a los nidos, los enfermos, y que por 10 tanto, los padres permiten estudiarla ya que aún después del matrimonio se puede continuar ejerciéndola, atendiendo los hijos, los hermanos, es decir la familia.

En cuanto a la herencia militar aún cuando no es tan evidente a primera vista, como las anteriores, es realmente muy marcada.

En Europa desde Las Cruzadas hubo una mezcla muy aguda de tres elementos: enfermería, religión y milicia; habla monjes que eran soldados, y hubo una orden especial de enfermeros que se llamaban "Caballeros Hospitalarios", en los cuales, una sola persona reunía estos tres caracteres: ser enfermero, religioso y militar al mismo tiempo.

Y unas enfermeras religiosas decían al respecto: "Las Cruzadas produjeron las órdenes militares de enfermeros y legaron a la posteridad el espíritu de disciplina que debe reinar entre los consagrados al enfermo ${ }^{10}$.

Florence Nightingale con su participación en la Guerra de Crimea formaliza la enfermería como servicio de apoyo logístico a los ejércitos; y para ello recoge un grupo de enfermeras religiosas para llevarlas ala guerra. Posteriormente, cuando se abre la Escuela de Enfermeras de Santo Tomas para preparar enfermeras para las guerras, se organiza con todos los elementos como recurso de retaguardia.

Todo esto potencializa la influencia de la visión militar en enfermería. De ahí que cuando se analiza el reglamento de la Escuela de Santo Tomas, se puede ver claramente que era un reglamento de corte militar, con horarios, uniformes, y una costumbre muy significativa, ILamarse por el apellido, en vez de hacerlo por su nombre.

La creación de la Cruz Roja profundizó la relación enfermería - ejército, que ha existido desde que ha habido guerras y por 10 tanto heridos.

La ideología militar tuvo su efecto en la internalización de valores que promovieron una fuerte jerarquización en el personal, supervisoras, una alta normatividad, horarios y uniformes muy estrictos, distintivos, títulos, etc. Todo 10 cual está muy relacionado con el concepto de disciplina.

Enfermería tiene entonces mucha relación con éste tipo de organizaciones, como las órdenes religiosas y el ejército, que son profundamente jerarquizadas.

Pienso yo, que la herencia antropológica en América Latina tiene mucho peso, solamente que no tenemos conciencia de ello. Muchos de los procedimientos que nosotros hacemos son costumbres ancestrales, que se han ido modificando, modernizando, cambiando de nombre para hacerlos más "científicos".

Mirándola de una manera general, con frecuencia cuando hablamos de una herencia antropológica, nos referimos o pensamos solo en la herencia indígena, aún cuando la verdad es que tenemos muchas fuentes, por ejemplo de la enfermería española. Y más, si tenemos 
en cuenta que la medicina o las prácticas de salud españolas eran resultado de influjos mediterráneos, del cercano oriente (medicina árabe y judía), de la medicina ayurvédica; que habían sido dominantes hasta las vísperas del "descubrimiento" de América.

$Y$ todas éstas influencias en la medicina española son fáciles de entender, si recordamos que durante varios siglos antes de los viajes de Colon; Sevilla (donde vivían los Reyes Fernando e Isabel) estaba ocupada por los judíos; su vecina Granada, lo era por los árabes, lo mismo que su otra vecina, Córdoba (la ceca del mundo islámico).

Virginia Gutierrez de Pineda caracteriza el legado español, así:

- tenía como base la cultura cristiana, con sus rasgos mágicos asociados (pecado = enfermedad);

- había influencia de la herencia griega, con los principios de Hipocrates;

- posibles aportes romanos que influyeron en la colonización;

- la llegada del mundo árabe y de las invasiones africanas a España dejaron una herencia mágico-médica (por ej. el mal de ojos) ${ }^{13}$.

La misma autora plantea que somos un país triétnico cultural y yo considero que esto necesariamente ha influido no solo en las prácticas de salud, si no también en los procedimientos de enfermería. Es decir, nosotros los colombianos tenemos tres aportes o herencias étnicas: 1) el legado de los nativos americanos, 2) el legado africano, y 3) el legado español, que no es solo herencia puramente española, sino con mucha influencia árabe e incluso también con influencia de la medicina de la india y de otras que habían influenciado antes a la misma medicina árabe.

Este es un tema en general poco estudiado. Hay algunos trabajos en relación con la medicina, pero de enfermería es muy poco, casi nada lo que se encuentra al respecto.

Un ejemplo de la influencia española, serían los diferentes tipos de aguas aromáticas, cada una con un objetivo especial, que le dan a los pacientes en las clínicas privadas, y especialmente, en aquellas regentadas por congregaciones religiosas. y que en general, se utilizan en las zonas de mayor influjo cultural hispano.

El uso de los alimentos "calientes" para cuando se tiene frío en el estómago, el uso de los baños con determinadas yerbas, yen general toda la parafernalia de la medicina ayurvédica. Estas cosas las aprendimos con la metodología que llamamos hoy la "pedagogía invisible", es decir la que no se explícita, la que se enseña con la demostración práctica, con el ejemplo diario. Y de ello no se podía hablar en los medios "científicos", por lo menos hasta hace algunos años, cuando se empieza a aceptar la medicina naturista.

De la influencia de la medicina árabe, a través de España, por ejemplo el recitar textos del Corán, tuvo en el momento de la conquista tan considerable poder para curar que se les reconocía como profesión, la de ensalmador, y ellos aplicaban versos de las sagradas escrituras y los complementaban con rituales curativos, usándolos ya en forma de recitativos sobre las heridas y aplicando algunas veces remedios de otra naturaleza.

Hoy en Colombia se denomina ensalmar el proceso curativo de mordedura de serpientes. 
Yen los Llanos Orientales, en Antioquia, en el Tolima, yen general en las zonas ganaderas, se rezan los parásitos (garrapatas, nuches, etc.) de las reses.

Por otra parte, muchas de las actividades, de los "quehaceres" de las enfermeras (aprendidos en las escuelas o no), -y podemos con cierto cuidado en el análisis de nuestras "rutinas", hacer conciencia de ello- son tomadas de la medicina popular, o tradicional como prefieren llamarla otros. Serla muy interesante hacer un estudio al respecto, teniendo en cuenta los diferentes grupos indígenas que poblaron las respectivas zonas del país ${ }^{22}$.

Afortunadamente, ya en la Carrera de Enfermería de la Universidad Pedagógica y Tecnológica de Colombia - UPTC, se promueve una línea de investigación en torno a las medicinas tradicionales, tratando de lograr la comprensión de la concepción que sobre vidamuerte, salud-enfermedad, viendo como éstas civilizaciones conciben la unidad hombrenaturaleza - cosmos, para así poder identificar y valorar los comportamientos que perduran en nuestras culturas y que tienen manifiesta procedencia aborigen ${ }^{1}$.

Para hablar de la historia de la enfermería hay necesidad de hablar de historia de la "medicina", no como profesión sino como cuerpo de conocimientos. Y de la historia de los hospitales, ya que eran las instituciones donde se hacía el cuidado de los enfermos, organizado por el gobierno español.

Yen general, se hace indispensable ir observando toda la influencia extranjera que vamos recibiendo en todos los órdenes de la vida humana, y la cual se va acentuando cada día mas debido desarrollo de las comunicaciones, la internacionalización de la economía yen general el acercamiento de todos los países entre si, a través de diferentes mecanismos.

Uno de los factores más importantes para lograr la conquista fue la religión. Al ILegar los españoles se encontraron ante un panorama de inmensa riqueza y posibilidades de explotación en manos de indígenas "bárbaros y politeístas". Esto ofrecía al conquistador la justificación de someterlos por la fuerza e imponerles la fe católica, que el indio adoptaba mas por convicción, por salvar su vida del despojo, crueldad y explotación a que era sometido.

Sin embargo, la inmensa mayoría de los indígenas no abandonó su visión politeísta, ya que el contenido abstracto de las enseñanzas cristianas les resultaba difícil de comprender.

Esta situación fue conformando una amalgama de "religiones" que marcó con un sello especial al "pueblo novohispano", como lo llama la enfermera mexicana Edda Alatorre 2. Ubicándonos en la época de la conquista española, encontramos que los conquistadores encontraron seis tipos diferentes de manipuladores del poder mágico, enclavados institucionalmente, con funciones en algunos casos específicos, yen otros, mezcladas:

1) asociado a la religión, (sacerdote);

2) vinculado al poder político;

3) la cabeza médica;

4) los agoreros y adivinos asociados a la milicia;

5) los controladores de la naturaleza, asociados a la economía; y 
6) los conductores de los ritos de paso o dirigentes del proceso sociabilizador generacional.

Según Virginia Gutierrez de Pineda $^{13}$, cuando los españoles se impusieron culturalmente a los aborigenes, el shaman fue perdiendo sus prerrogativas institucionales y se empieza a proyectar con el uso de la magia agresiva. Esta magia enfrenta la enfermedad que conduce al deceso, sea mediante rituales mágicos o acciones mortíferas de naturaleza física. En algunos casos representa la defensa del débil frente al poderoso.

Surgía también una medicina en la que se mezclaban la razón con la causalidad mística, que establecía dos tipos de etiología a las enfermedades: una que reconocía las causas aprendidas en libros y otra en que se atribuía a maleficios el origen del problema.

De tal manera, poco a poco se irían separando dos tipos de atención a la salud. Una practicada por el médico que llegaba de España y que prodigaba sus servicios a la clase económicamente poderosa; otra de médicos indígenas que fieles a sus tradiciones atendían a su pueblo, general mente a escondidas, puesto que eran perseguidos por brujería y entregados a la Santa Inquisición ${ }^{2}$. Guillermo Restrepo ${ }^{17}$, al hablar de la época del Colonialismo Español, anota que "la mayoría de la población era atendida por curanderos, los cuales en general, tenían un gran prestigio en la comunidad indígena, ya que eran los herederos de los métodos tradicionales de atención a las tribus".

Frecuentemente las expediciones de los conquistadores venían acompañadas de médicos españoles, cuyo trabajo estaba dirigido a atender la tropa. Muchos de éstos médicos quedaban al servicio de los encomenderos y autoridades españolas de la colonia.

La atención de salud se perfilaba con marcada discriminación a los naturales. Cierto es que fueron llegando de España diversas órdenes religiosas de hombres y mujeres; cierto también que llegaron médicos; también se nos ha dicho que ellos atendieron a los indígenas enfermos con verdadera "abnegación y sacrificio". Sin embargo, en diversos documentos de esa época se puede constatar que los españoles eran atendidos por españoles y los naturales eran atendidos por los propios indígenas ${ }^{2}$.

Alberto Vasco, citado por Velandia ${ }^{20}$, caracteriza esta situación, de la siguiente manera:

1) existía un grupo de médicos españoles vinculados a las cortes virreinales;

2) habrá también un grupo de médicos españoles o criollos vinculados a las nuevas clases que se formaban en América;

3) la característica común a todos ellos era de satisfacer una demanda cada vez mas creciente, para lo que necesitaban fundamentalmente de conocimientos "prácticos";

4) habrá un desestímulo de todo conocimiento en profundidad por las razones descritas y por la ausencia total de instituciones que lo permitieran;

5) se producía la marginación completa de los indígenas y los esclavos, a quienes no había que curar si no reponer;

6) el ingreso de los profesionales era alto, debido al aumento de una clase con capacidad de consumo y a la ausencia de formación profesional en el país.

En cuanto a la organización de Hospitales y su apoyo por parte del gobierno español, 
podemos recordar algunos hechos definitorios.

Parece ser que en el año 1513 ya existía en Cartagena el Hospital de San Lázaro, aunque no fundado con todas las de la ley, si recibía ayuda por parte del Rey, quien solo hasta 1610 dio la orden de fundación. También debió recibir el nombre de San Lázaro por ser allí a donde acudía más cantidad de gente afectada por la lepra.

Y parece ser que fue en ésta ocasión cuando liego Pedro Claver a Cartagena y empezó a dar los servicios espirituales y servicios de enfermero curando las úlceras de los leproso $^{18}$. (El subrayado es nuestro).

Según algunos documentos originales en manos del Médico Palomo Del Real, "Pedro Claver, español catalán, en el año de 1617 ejercía medicina empírica y enfermería, junto a su apostolado en el Hospital San Lázaro, del Pie del Cerro"24. Se refiere al Cerro de la Popa, a donde había sido trasladado para alejar los leprosos del centro de la ciudad.

Según Zabaleta, en 1768 los jesuitas (y Pedro Claver lo era), ya vivían en Cartagena en un terreno amplio (Colegio de la Compañía de Jesús, en la Calle de San Juan de Dios) donde colocaron el Hospital General. Y según el mismo autor, parece ser que por ésta época cambió su nombre por el de Hospital de San Juan de Dios. (Nota: seguramente de allí más tarde esa calle de la Ciudad de Cartagena tomó su nombre).

El cambio de nombre del Hospital General por el de San Juan de Dios, debió coincidir Con la llegada de España de los Hermanos Hospitalarios de San Juan de Dios.

Según Gilig, citado por Soriano Lleras $^{18}$, "parece ser que los Hermanos de San Juan de Dios llegaron primero a la ciudad de Cartagena y allí crearon un Hospital Con su nombre".

Posteriormente se le llamo Hospital de Caridad y con el nombre de Hospital de Santa Clara empezó a denominarse desde 1923 y continuó funcionando por muchos años en el Convento de las Clarisas ${ }^{24}$. Este nombre y ubicación se mantiene hasta comienzos de la década del 70 (1973), cuando se construye un moderno Hospital en la zona de Zaragocilla de la ciudad y recibe el nombre de Hospital Universitario de Cartagena y el antiguo Convento de las Clarisas se está convirtiendo por acción de la cadena hotelera Sheraton, en un Hotel de cinco estrellas, el "Santa Clara".

Como hemos podido observar, todos estos cambios de nombre del Hospital, muy seguramente se dieron por influencia de las Hermanas de la Caridad de la Presentación, cuando llegan en 1886 y cuando salen en 1923 y la Junta Reformadora del Hospital - que según Zabaleta Jaspe eran masones - trae enfermeras seglares.

Según Eusebio Guerrero Pérez, citado por Zabaleta, hacia el año 1878 o 1879 el Convento de las Clarisas fue adaptado para servir de Hospital, habiendo sido encargadas de su administración las Hermanas de la Caridad de la Presentación, procedentes de Francia. (Nota: lo cual corroboraría el cambio de nombre del Hospital).

Yen el mismo tenor se dice que los Hermanos de San Juan de Dios atendieron el Hospital hasta mediados del Siglo XIX y desde 1886 hasta 1923 las Hermanas de la Presentación. 
Sin embargo, la Hermana de la Presentación, Beatriz Alvarez, en su concienzudo trabajo: "Hermanas de la Caridad Dominicas de la Presentación de la Santísima Virgen. Los diez primeros años de su implantación en Colombia", dice que las hermanas llegaron directamente a Bogota en 1873.

Y según el mismo Zabaleta, existe una nómina de 1793 del Convento-Hospital San Juan de Dios.

Según todo lo anterior, la mejor orientación para saber que orden religiosa atendía a los enfermos en cada Hospital, parece ser el nombre que le van dando a los hospitales donde van llegando.

En cuanto a la historia hospitalaria de Santafé de Bogota, en 1564 se fundó el primer hospital. Fue fundado por el Arzobispo Fray Juan de los Barrios y Toledo quien donó unas casas de su propiedad situadas en la Calle de San Felipe y que ocuparon el lugar que hoy ocupa la Catedral y la Sacristía de la misma. Este Hospital tomó el nombre de San Pedro. Los clérigos fueron quienes tomaron la iniciativa en la fundación de dicho hospital y los servicios eran estados por los mismos ${ }^{18}$.

El 2 de Diciembre de 1595 Felipe II concede licencia a los religiosos de la orden momástica de San Juan de Dios, que había sido fundada en Granada en 1540, para que puedan pasar a América a fundar hospitales yen 1603 liega a Santafé de Bogota San Juan de Buenafuente, fraile de la Orden de San Juan de Dios. Viene provisto de la real licencia expedida por Felipe II para que tome posesión del Hospital San Pedro, mas no puede cumplir la voluntad real. El Arzobispo Lobo-Guerrero es patrono del Hospital de San Pedro y "se le opone terca y enérgicamente"14.

De ésta manera aparece por primera vez en territorio nacional la orden de San Juan de Dios, que se ve burlada por el Arzobispo, quien de paso burla al poder civil que representa el Rey ${ }^{14}$.

Frustrada en 1603, en 1630 (66 años después de su fundación), Felipe III consigue que la administración del Hospital quede a su cargo y de tal manera, en 1634 el Cabildo Eclesiástico de Santafé solicitó al Prior de la Orden (quien residía en Cartagena) que mandara algunos religiosos a Santafé, para servir en el Hospital. Con tal fin que se trasladó a ésta ciudad Fray Gaspar Montero y ILegó a ella en 1635 y entonces le fue entregado el edificio de una manera solemne por el Arzobispo Fray Cristobal de Torres, quien le dió también el manejo de las cuentas del establecimiento y lo nombró Prior y Médico de los Frailes. El Hospital cuenta con 17 camas. Más tarde serán 30: 20 para hombres y 10 para mujeres ${ }^{18}$.

Martinez Zulaica explica la evolución de la disputa, diciendo: "Los deseos reales fueron cumplidos mas que nada por la presencia en Santafé de un nuevo Arzobispo, quien se avino a condescender con la voluntad del Rey austriaco". El 20 de Julio se firmó un acuerdo con los canónigos en virtud del cual los frailes quedaban como "ministros y sirvientes", sin tener propiedad sobre el Hospital ni sobre las limosnas que se les dieran ${ }^{16}$. 
Entre 1630 y 1634 hay una epidemia de tifo exantemático (llamado entonces "tabardillo"), que causa estragos en Santafé y forzó a improvisar otros hospitales mientras duró. Resulta lógico suponer que ésta peste debió poner bien de manifestó la falta de personal hospitalario (de enfermería?) y ser un factor convincente para que el Arzobispo Torres accediera a que los frailes hospitalarios se encargaran de su manejo, como "ministros y sirvientes"14.

Pero veamos como era el desarrollo de la enfermería en España por esa época.

Para ello, debemos conocer la historia del Hospital de la Santa Cruz de Barcelona, donde parece ser se empezó a organizar la enfermería, como tal.

El Rey Martin el 1 de Febrero de 1401 comenzó la preparación del Hospital de la Santa Cruz; a lo largo de 1401 a 1412, se fueron incardinando en ésta nueva institución los restantes hospitales de la ciudad. Se tomó la decisión de redactar un nuevo reglamento, el cual fue promulgado en 1417 y es, según Cecilio Eseverry ${ }^{9}$, "el punto nuclear de donde proceden los primeros pasos serios de la moderna organización hospitalaria española en general y de la enfermería en concreto".

La figura del Prior en el Hospital es importante. Debía ser: "sacerdote, devoto y sincero y se ocuparla principal mente de la capilla del hospital".

"La moderna figura del profesional de enfermería aparece fuerte, clara, precisa, necesaria".

"También establecieron y ordenaron que en el hospital haya una buena e idónea persona entre las demás, que tenga título de enfermero, el cual de be residir de día y noche en el hospital, y que especial mente se responsabilice, como corresponde a su oficio, de recibir y acoger adecuadamente a los pobres enfermos que lleguen al hospital, cuidándolos y atendiéndolos de la siguiente manera:

En primer lugar, que los lave o les haga lavar los pies y limpiarse donde yen la forma que corresponda.

En segundo lugar, que preparen a cada uno su cama limpia donde puedan descansar y tomar algo de comer.

En tercer lugar, que después de que el pobre paciente haya descansado en su cama y confortado con un poco de comida, acto seguido de parte al Rector de la Capilla, que cuida de las almas, para que lo visite y le administre la confesión y los demás sacramentos de la Santa Madre Iglesia; si fuera necesario el propio Rector, además de las otras cosas, en dicha confesión procurará interrogar y escrutar bien y con diligencia si lleva dinero consigo, y después que bienes posee yen que lugar los tiene. De todo lo cual el Rector debe hacer memoria, encargando al pobre paciente, convenciéndole graciosamente y de buenas maneras, animándole e induciéndole, que por su propia voluntad lo diga y manifieste todo explícitamente al Escribano de aprovisionamiento y al enfermero, los cuales deberán interesarse por estas cosas, para que el dinero, las ropas y los otros bienes estén a buen recaudo y para que el pobre paciente pueda recuperarlo cuando esté curado. Y una vez hecho esto, el enfermero deberá hacerle tomar agua y hacerle reconocer por los médicos, y con 
todo el cuidado deberá preparar y dar aquellas medicinas y alimentos que sean prescritos por los médicos".

"Y después el escribano de aprovisionamiento y el enfermero, deberán quedarse junto al pobre paciente para interrogarlo e investigar, bien y con diligencia, con buenas y amables palabras, en primer lugar sobre su nombre y lugar de residencia y sobre el trabajo que acostumbra realizar".

"Más adelante, sobre el dinero, la ropa, derechos y bienes, muebles e inmuebles, que tenga el paciente y le pertenezcan de alguna manera. También sobre las deudas de que fuera acreedor y, por el contrario, sobre lo que le deba a otras personas, a fin de que antes de su muerte puedan tener un conocimiento real y exacto de la situación".

"Y todas esas cosas que declara el pobre paciente, el Escribano de aprovisionamiento y el Enfermero, deberán anotarla, indistintamente, es decir cada uno en su cuaderno, anotando en primer lugar las ropas y el dinero que el pobre paciente lleve consigo, a continuación todo lo demás que haya declarado, comunicándolo después al Rector, para que pueda comprobar si las cosas anotadas concuerdan con las que el pobre paciente haya confesado. Y si por casualidad uno de ellos estuviera ausente y el paciente estuviera en tal estado que corriera inminente peligro de muerte, el que estuviere presente junto al Prior o el Rector deberán hacerle el interrogatorio y escrutinio, pasando después al que estaba ausente el inventario realizado. $\mathrm{Y}$ si el paciente tuviera dinero o monedas consigo, el Enfermero deberá tomarlas y conservarlas mientras se comprueba si el paciente vivirá o morirá. Y si vive, dichas monedas y todas las demás cosas que llevara consigo al entrar al hospital, le serán devueltas integralmente y sin retardo alguno una vez ésta curado. y si muere, aquellas junto con la ropa, los derechos y bienes antes mencionados, quedarán para el Hospital, conservando el enfermero la ropa que el paciente llevaba encima, en la guardarropía del propio hospital, poniéndola en orden: es decir, que la ropa del difunto no sea mezclada con las demás, sino que sea atada y empaquetada separadamente la una de la otra, a fin de que la venta pública que se haga después de ésta ropa, la cual se hará separadamente la una de la otra, pueda ser comprobada por el Escribano de aprovisionamiento con los inventarios de lo que se haya sacado a la venta pública que el Enfermero debe haber hecho mediante un corredor público y un notario o un juez. y se deberá responder y dar cuenta y razón del dinero que se haya recibido 0 encontrado en las bolsas de los difuntos, presentándolo al escribano de aprovisionamiento, al Receptor y Distribuidor General del Hospital, el cual deberá acusar recibo en sus cuentas de aquella cantidad o cantidades que por ésta razón haya recibido del Enfermero. Extenderá en el momento de la recepción una certificación del Escribano de aprovisionamiento, el cual se dirigirá al Censor. Cuentas, para que el Receptor en el rendimiento de cuentas delante del Censor pueda justificar con ésta Certificación ésta y otras cantidades semejantes recibidas, y el Censor podrá aceptarlas sin escrúpulo alguno".

"Queda declarado y expresamente claro, sin embargo, que el enfermero no deberá, ni le será permitido dar a nadie, aunque sea servidor o criado del Hospital, ninguna de estas 
ropas, ni ninguna otra cosa, sea o no importante, a no ser que sea por orden expresa de los honorables Administradores, de cuya orden deberá darse constancia por escrito al Escribano de aprovisionamiento. Tampoco el Enfermero permitirá que ningún pobre enfermo, de los que estén en el Hospital, salga del mismo sin estar perfectamente curado de su enfermedad, a fin de que, como ocurre muchas veces, cuando se van sin estar del todo curados, por su poco cuidado recaen y luego han de volver al Hospital, por lo que al hospital le representa un doble perjuicio. Pero si alguno de los pacientes conscientes de su enfermedad no desea quedarse para una curación perfecta, entonces que le sea permitido irse, haciéndole al Enfermero la advertencia de que en adelante no espere del Hospital socorro alguno".

"Por otro lado deberá el Enfermero visitar, ver y reconocer ordinariamente cada día y cada noche, a todos los enfermos, sean hombres o mujeres, que haya en el Hospital; por la mañana dos veces y después de la comida (del medio día) otras dos y sobre todo, sin ninguna excepción, en las horas de la comida, a fin de que pueda observar su forma de comer y si la comida que les ha sido preparada, probando y comiendo de ella, es buena y suficiente. $Y$ durante la noche, es decir, antes de medianoche, otra vez. Y después de medianoche, otra vez, para que pueda ver la situación de cada uno, ordenando y solicitando continuamente a los Servidores que estén dispuestos a servir a los enfermos, que estén junto a ellos y que sean solícitos en darles la comida y medicinas en las horas que hayan sido previstas por los médicos, y que los haga mantener limpios, así en la comida como en las demás necesidades; estos servidores, cuyo número será fijado por los honórales administradores y por el Enfermero, deben atenerse al reglamento, prestos y a disposición del Presidente. Y si alguno de ellos contraviniere de alguna manera éstas ordenanzas, el Presidente, el Prior y el Enfermero tendrán poder y plena facultad para trasladarles y cambiarlos, mientras no sobrepasen el número establecido, ordenado por los honorables administradores, deduciendo a cada uno de ellos el salario o liquidación que estime conveniente. $\mathrm{Y}$ el Escribano de aprovisionamiento deberá escribir y mantener, según su criterio, en su libro de aprovisionamiento y hacer el ajuste de salario, sin esperar el juicio y el consentimiento de los honórales administradores, si considera que el salario era desmesurado y excesivo".

"Por otro lado, el Enfermero deberá administrar y dirigir las personas que estarán dispuestas a hacer las cuestaciones que se hacen ordinariamente cada día por la ciudad junto con los asistentes, así como aquellas otras que tienen encomendada la recaptación que se hace con las bandejas en las iglesias. Tanto por lo que se refiere a las obras de caridad, como para los entierros, e incluso el mantenimiento del Hospital. Estas personas serán en el número que estimen conveniente los honorables administradores, y deberán atenerse al reglamento, sometidos y a disposición del Enfermero".

"Estas personas deberán responder de las monedas que procedan de dicha cuestación y recaptación y aún del pan vendido, y deberán entregar estas monedas al Enfermero, cada día, después del mediodía; así como todas aquellas que favorezcan al Hospital, ya sean cesiones hechas por testamento o de palabra; o bien de limosnas secretas y privadas deberán 
ser recibidas por el Enfermero, en presencia del Escribano de aprovisionamiento o en su ausencia, en presencia del Prior, a fin de que el Escribano de aprovisionamiento, para poner en evidencia cualquier tipo de fraude, lo pueda poner y escribir claramente en su cuaderno. Y el Receptor y Distribuidor General, con este cuaderno, dilucidar la cuenta del Enfermero o cualquier otro que ostente el cargo, cada semana, es decir, el lunes, de todo lo que haya recibido de la semana anterior; y el Enfermero, en este mismo día, sin dilación ni excusa alguna, deberá librar Integralmente todo lo que por dicha razón haya recibido el Receptor, quien personalmente, deberá firmar en el cuaderno, ratificando con su firma haber recibido la cantidad recibida del Enfermero, poniéndola como recibida en sus cuentas; el Censor de cuentas, mediante este cuaderno, aceptará las cuentas teniendo este recibo y los demás parecidos como auténticos y sin escrúpulo alguno".

"Además el enfermero tendrá el cometido y el encargo de pagar a las nodrizas que alimentan a los niños enfermos en el hospital, dando el Receptor y Distribuidor General de antemano una orientación de la cantidad que crea posible, anotándosela en su libro común para hacer memoria; de dicha cantidad el Enfermero, delante del mencionado Escribano de aprovisionamiento, que tiene anotadas y registradas estas nodrizas -en su libro de aprovisionamiento, deberá hacer las particulares remuneraciones y pagos, en ésta forma; es decir, que el Enfermero haga dichas remuneraciones y pagos a las nodrizas y el Escribano de aprovisionamiento escriba en su cuaderno don de tenga la cuenta anotada a las nodrizas y con dicha cuenta hacer de vez en cuando, sin escrúpulo alguno, un albarán, dirigiéndolo al Receptor con la suma total de dichas remuneraciones y pagos hechos por el Enfermero durante aquel tiempo. En virtud de éste albarán, el Receptor poniendo la fecha de sus cuentas con la cantidad relacionada, satisfaga la anotación o anotaciones al Enfermero en su libro común, la cantidad o cantidades que por dichos pagos haya desembolsado"9.

Todavía no ha aparecido el nombre de Enfermera, pero si sus funciones, sus tareas, su "profesionalidad", comenta Cecilio Eseverry, sin embargo, y a mi manera de ver, el cargo de Enfermero, mas parece corresponder al administrador de la sala de enfermeros, que a la persona que los atiende en sus dolencias y los cuida como personas.

Hasta aquí, parece referirse a las salas de hombres. Respecto a las mujeres, tiene un acápite especial para La mujer encargada de las enfermas.

"Además: dispusieron y ordenaron que en el hospital fuera nombrada y elegida por los honorables administradores una mujer de reputación, honesta y de buenas costumbres, que resida permanentemente en el Hospital y se encargue especial mente de las mujeres enfermas que haya: de tal manera que haga administrar y distribuir la comida y las medicinas en las horas que ordenen los médicos y barberos, instando y solicitando, de día y de noche, a las Sirvientes destinadas a servir a las enfermas, para que faciliten cumplidamente todas las cosas necesarias y las mantengan limpias, tanto de parásitos como de suciedad; dichas sirvientes deberán estar plenamente sometidas, a las órdenes y a disposición de ésta mujer. Dándole plenas facultades para poner, cambiar o variarlas, así como reducirles el salario o 
salarios que crea conveniente; y el Escribano de aprovisionamiento deberá anotarlo y continuar con el salario o salarios que haya ordenado dicha mujer, sin esperar la opinión, ni el consentimiento de los administradores, a no ser que considere que el salario es desmoderado o excesivo. Ésta mujer deberá tener a disposición la ropa, tanto de la cama como toda la demás, que le habrá sido entregada por el Enfermero, para el uso y servicio de las enfermeras, y deberá dar cuenta y razón de las mismas al propio Enfermero que las tiene inventariadas y anotadas junto con las demás".

Aquí se puede observar muy claramente el origen de la enfermera como jefe de sala, pero "de todas maneras" dependiente del enfermero.

Se definen también las funciones de la Mujer encargada de los niños.

"Además: ordenaron que en el hospital hubiera una mujer de reputación, honesta y de buenas costumbres, para que tuviera una especial atención a los niños, es decir, que los cuide y los mantenga limpios; a ésta mujer le serán asignadas las sirvientes que los honorables administradores crean conveniente, a fin de que dicha mujer, a través de ellas, pueda facilitar a los niños todo lo necesario; ésta mujer deberá dar razón de toda la ropa, tanto de las camas como las demás, las cuales le serán entregadas para el uso y el servicio de los niños, y también de su persona y aún de las sirvientas. El Escribano de aprovisionamiento, haciendo nota de aquellas, en el mismo lugar yen la misma forma que los demás oficios, en virtud del presente reglamento, procurará poder dar razón de todo en el reconocimiento general hecho por los honorables Administradores para la preservación de Hospital. Dichas sirvientas deberán someterse a la obediencia de ésta mujer, que tendrá plena facultad para trasladar o cambiarlas, completamente a su disposición, mientras no sobrepasen en número al establecido por los honorables administradores. Y el Escribano de aprovisionamiento deberá anotarlas en su libro de aprovisionamiento, con el salario ordenado por ella, sin esperar la opinión ni el consentimiento de los honorables administradores, a no ser que dicho salario sea desmoderado o excesivo".

"Aún más: ésta mujer deberá dar cuenta y razón, tanto de todo aquello que tenga encomendado para el cuidado de los niños y por cualquier otra razón, que le haya sido entregado por cualquier persona, en secreto o públicamente, como de todo aquello que ella misma o las sirvientas puedan hacer o de alguna otra forma puedan obtener honestamente del Receptor y distribuidor general o del Escribano de aprovisionamiento. Esto es, del Receptor, de las monedas destinadas a ella para que acuse recibo en sus cuentas; y del Escribano de aprovisionamiento, de la ropa, para que lo anote en su libro de registro, de cuyas cosas, así como de los niños, ésta mujer no podrá disponer de ninguna manera sin el consentimiento y la voluntad de los honorables administradores, y de dicho consentimiento deberá haber un documento escrito del Escribano de aprovisionamiento"' .

Aquí se visualiza de manera clara, lo que más adelante serían las Ayudantes de Enfermería, y se hace énfasis en el papel de "Ecónoma", de la Jefe de Sala.

Más tarde el Emperador Carlos I y Doña Juana establecieron unas constituciones 
funcionales, que dieran "una normativa funcional interna adecuada" a los hospitales existentes. y de alguna manera comenzaron por el Hospital mas significativo, más notable, el Hospital Real de la Ciudad de Santiago. Después estas constituciones resultaron básicas para los restantes hospitales reales del país. Era en 1524.

Aquí se habla ya del Enfermero Mayor. (La cita ésta en su estilo original).

"Iten mandamos que haya un Enfermero Mayor, que sea hombre cuerdo, e de buena conciencia, e autoridad, el cual tenga salario competente, en cada un año, por razón del dicho oficio, e demás desto se le de comer en la dicha casa. El cual dicho Enfermero Mayor jure al tiempo que fuere recibido al dicho oficio en manos del Administrador, que el no hará ni consentirá hacer fraude, ni engaño en cosa alguna de las que en la dicha casa sean. Y visitará continuo las enfermerías, e hará hacer las camas en su tiempo y tendrá principal cuidado que se visiten los enfermos, como convenga, les den de comer. y todas las medicinas que les mandan dar a sus tiempos, todo muy concertado, e que tengan cuidado de procurar que los Capellanes visiten los enfermos, especialmente los que estuvieren en peligro y que se les den con tiempo los Santos Sacramentos. y que tenga a buen recaudo la ropa...".

"Tenga siempre cerrada la puerta de la Enfermería, ya que ninguno de casa salvo el Médico, o el Enfermero Mayor, entre en la dicha enfermería, donde las mujeres estuvieren, sin mandato expreso del Administrador, ni hable con mujer alguna del las aparte"?.

Aquí aparece la figura de lo que muy posteriormente sería la Directora del Departamento de Enfermería del Hospital y que se encuentra a comienzos de siglo en el Hospital Santa Clara de Cartagena.

Más adelante, en la enfermería española del Barroco (Siglo XVII y XVIII), se encuentra: "El Enfermero Mayor tenga particular cuidado, que todos los Enfermos, que por tiempo entraren en el Hospital, se escriban en un libro, que ha de haber en cada casa para este fin, poniendo el nombre, y sobrenombre, la patria, si es soltero, o casado, el nombre de su mujer, los nombres de sus padres, el vestido que trae, en que Sala se acuesta, y a que número de camas, y cuando alguno muriere, yen esto se pongan las diligencias convenientes, y necesarias para observar la buena Hospitalidad...".

Volviendo a ver que pasaba en Santafé por esa época, vemos que en 1723, teniendo en cuenta que el lugar que ocupaba el Hospital era muy estrecho e inadecuado, se empezó a construir otro al occidente de la ciudad de Santafé (de ese entonces, que hoy corresponde al llamado centro de la ciudad), de acuerdo con pianos de la ciudad de Granada. Ésta construcción se terminó en el año de 1739 y se le llamó inicialmente de Jesús, Maria y José ${ }^{18}$.

En 10 de Enero de 1739 se inauguró la enfermería de mujeres cuya obra se debió en gran parte al Virrey Solís ${ }^{7}$.

Poco después en 1743 los Frailes de San Juan de Dios (Religiosos Hospitalarios) se hicieron cargo del Hospital y desde entonces lleva el nombre de "San Juan de Dios". Por casi dos siglos estuvo situado allí mismo junto a la Iglesia del mismo nombre. (Calles 11 y 12, carreras 9 y 10). 
Según Soriano Lleras $^{18}$, en 1762 se colocó la Enfermería de Mujeres de San Juan de Dios, cuya obra llegó a 500 pesos.

En 1804 los Frailes atenderían las salas de hombres y para las mujeres había sirvientas dirigidas por una señora.

Por su parte en Medellín, en 1801 cuando hubo una gran epidemia de viruela, ya existía un Hospital, también al cuidado de los religiosos de San Juan de Dios.

Por esa época, los cirujanos y los médicos solo eran los religiosos, una profesión meramente religiosa. Aunque los hospitales no eran de propiedad de los Hermanos de San Juan de Dios, éstos eran los asistentes de aquellos ${ }^{18}$.

Después del destierro de los Hermanos de San Juan de Dios en 1835 (siendo Presidente titular el General Francisco de Paula Santander), el Hospital volvió a ser administrado por personas seglares. Distinguiéndose entre ellas la Congregación del Sagrado Corazón compuesta de las más distinguidas damas de la alta sociedad.

Cuentan las crónicas que un grupo de respetables señoras filántropas (semireligiosas), compuesta por doña Vicenta Gutierrez Vergara, Francisca Pineda Valencia, Ana Josefa Quijano, Virginia García, Juana Lago y tres más, se organizaron en una asociación de caridad o congregación, que dieron en llamarse "Hermanas de la Caridad", bajo el patrocinio de San Vicente de Paul y la ayuda de la Sociedad de Beneficencia.

La señora Vicenta Yanguas de Galvis, a la cabeza de las señoras mencionadas, se hizo cargo de la administración del Hospital el 1 de Abril de 1857, mediante contrato oficial. Una de ellas asumió el cargo de Enfermera en la Enfermería de Mujeres ${ }^{7}$. (Esto deja en claro, que el término "enfermería"; era utilizado en ese entonces para designar las "salas de enfermos").

No se encontró referencias de estudios realizados por éstas personas; solo referencias a la forma de dividir el trabajo y las actividades de enfermería en el Hospital. En general, las actividades de enfermería eran realizadas por religiosas, o seglares de baja extracción social.

Desde 1856, varios señores notables de Bogotá, se propusieron hacer venir a las "Religiosas de la Caridad", para que sirvieran en el Hospital de la ciudad. La Junta General de Beneficencia autorizó al Síndico del Hospital para solicitar a la Superiora General de las Hermanas de la Presentación (Dominicana), que residía en Tours (Francia), el envío de las religiosas hicieron cargo de la dirección y el cuidado de los enfermos ${ }^{12}$.

El 22 de Septiembre de 1867, 125 años de ello estamos celebrando ésta semana, el Presidente Santos Acosta organizó la Universidad de los Estados Unidos de Colombia, a la cual se incorporó el Hospital de San Juan de Dios. La enfermería del hospital quedaba a cargo del los profesores de la clínica ${ }^{14}$. (Recuerdes que por esa fecha, ya habían salido del país los Hermanos de San Juan de Dios y no habían llegado todavía las Hermanas de la Presentación).

En 1873 llegaron procedentes de Francia por solicitud del Gobierno (a través del Síndico del Hospital San Juan de Dios de Santafé de Bogotá), las Hermanas de la Presentación. Seis 
hermanas llegaron el 26 de Mayo al Puerto de Sabanilla (hoy Puerto Colombia), y el 21 de Junio al Hospital de San Juan de Dios de Santafé de Bogota, que fue la casa donde las religiosas iniciaron su misión de enfermería en Colombia. A partir de esa fecha comenzaron la administración del Hospital San Juan de Dios ${ }^{12}$.

Numerosas directivas de hospitales, solicitaron también la colaboración de las hermanas. Según Zabaleta ${ }^{24}$, se encargaron de la administración del Hospital Santa Clara de Cartagena en 1878 o 1879. Según Alvarez ${ }^{3}$, esto ocurrió solo hasta 1884. Antes lo hicieron del Hospital de Medellín, en 1876; del de Barranquilla, en 1878; del de Santa Marta y el de Sogamoso en 1880; del Pamplona y Neiva, en 1882 y del de Honda, en 1883.

Es importante recordar que "fue en Conventos y Monasterios donde durante la Edad Media se ejerció y se aprendió la Medicina"6.

En Colombia las primeras enseñanzas sobre higiene y cuidado de los enfermos fueron impartidas por religiosos pertenecientes a las comunidades de los Franciscanos, Dominicos, Mercedarios, Capuchinos, Hermanos Hospitalarios de San Juan de Dios y Jesuitas $^{7}$. Y también de los Bethelemitas, según otros ${ }^{18}$. La enseñanza de enfermería, naturalmente se orientaba a las actividades que mas comúnmente desarrollaban, higiene y tareas domésticas.

Las comunidades religiosas vinieron al país entre 1564 y 1835 con el propósito de catequizar a los indígenas ${ }^{6}$.

El ejercicio de las denominadas actividades de enfermería estuvo durante tres siglos en Colombia en manos de religiosos, entre los cuales se han destacado por su trabajo los Hermanos Hospitalarios de San Juan de Dios, quienes fundaron además diferentes instituciones como el Hospital de San Pedro (boy San Juan de Dios), el Hogar Clínica San Rafael y el Manicomio Nacional en Santafé de Bogotá, y la Clínica de Reposo en Chía (Cundinamarca) $)^{7}$. También el Hospital de Cúcuta ${ }^{11}$.

En el Hospital San Juan de Dios, trasladado el 7 de Febrero de 1926 a la zona de la ciudad conocida popularmente como "La Hortua", por el nombre de la Hacienda a la cual pertenecieron los predios en que se construyó; antes de 1952 existía una distribución de la planta física de acuerdo a la escuela francesa, cada pabellón era atendido por una o dos enfermeras (sic), una religiosa y un médico interno. Las hermanas de la presentación servían como Enfermeros Jefes y administradoras del Hospital y del personal femenino ${ }^{14}$.

Los religiosos se encargaban de la administración de los hospitales y ésta actividad les redituaba importantes ganancias. y los religiosos españoles fueron perfeccionando cada día mas la administración de hospitales.

Pero, la profesión de enfermería, entendida como las acciones de atención a la salud, a través de una relación formal, establecida mediante un cierto convenio y a cambio de una remuneración; con acciones dirigidas al margen del propio núcleo familiar, no se daba entre los pueblos prehispánicos.

Y parecer ser, que tampoco se daba en la época del colonialismo español. La enfermería formaba parte de las actividades desarrolladas por una parte, por los religiosos 
administradores de hospitales, y por otra, par sirvientas u otro personal auxiliar de baja extracción social.

Por tal razón y a mi manera muy personal de analizar estos hechos, la profesión de enfermería en Colombia, se inicia en 1903 con la Escuela de Enfermeras de la Universidad de Cartagena.

La situación de las parteras era bien diferente, ya que, en primer lugar, sus servicios respondían a una necesidad natural, yen segundo lugar, existían desde la época prehispanica gozando de enorme prestigio entre su pueblo². Tenía la categoría de sacerdotisa, de socializadora, de consejera en asuntos matrimoniales, de educadora en salud; en suma, poseía la categoría de "mujer sabia"4.

Aún cuando en Colombia, esto no fue tan evidente, como en otros países de América Latina, por ejemplo, México, donde las mujeres aztecas, desempeñan las labores de parteras y pueden acceder a los dioses de duracion ${ }^{1}$. Aún cuando, éste es otro tema sobre el cual me mueve un gran interés en tratar de profundizar un poco más.

Vistos hasta acá los hechos, hasta la década del 20, la enfermería colombiana venía influenciada por la medicina francesa de la observación (individual) del enfermo; que era la que predominaba en todo el mundo "científico" o de la medicina occidental. Y es en éste momento cuando entra formalmente a la enfermería colombiana el enfoque de la medicina americana, orientada a la clasificación de los pacientes por especialidades y su consecuente reunión en salas por especialidades, para su manejo por grupos de diagnósticos, en vez de las antiguas "enfermerías de mujeres" y "enfermerías de hombres".

Es significativo anotar aquí que en Mayo de 1930 cuando se dictó un nuevo Reglamento para la Escuela de Enfermeras y parteras del Hospital Santa Clara, se le agregó al pensum la materia de: Organización Hospitalaria y Administración. Mientras que en las cinco asignaturas que conformaban el pensum de la Escuela de Enfermeras y Comadronas dependiente de la Facultad de Medicina de la Universidad Nacional en Bogotá, no aparecía todavía ninguna materia relacionada con el área administrativa.

$Y$ no es casual que sea justamente en Cartagena en donde aparezca este nuevo enroque, si tenemos en cuenta que las primeras "Instructoras" de la Escuela de Enfermería de Cartagena eran y fueron durante varios lustros, enfermeras procedentes de Panamá y quienes habían estudiado en la Escuela de Enfermeras del Hospital Santo Tomas, precisamente el Hospital norteamericano que funcionaba en la zona del Canal, con todas las características de enclave que han facilitado el desarrollo de una cultura americana en esa región.

La enfermería que llamamos "moderna", es decir influenciada par Nightingale, está profundamente impregnada de las concepciones inglesas sobre la salud de mediados del siglo XIX, que eran reflejo de la "medicina urbana" de que habla Michel Foucault, citado por Velandia $^{19}$, con sus métodos de vigilancia (observación), de hospitalización, de la Segunda mitad del Siglo XVIII en Francia, unido al concepto inglés de la medicina de los pobres y los obreros. 
Los funcionarios sanitarios hablan reaccionado contra la tesis del contagio de 1700 y estaban convencidos de que "aires y aguas" (el medio físico) determinaban grandemente la salud de cualquier pueblo. Dentro de éste contexto se enmarcan las concepciones de Florence Nightingale, y "aún cuando los bacteriólogos arrojaron nuevas luces sobre éste problema después de 1875 , ella continuó ridiculizando la idea de infección y el ideal sanitario, dentro de los límites sugeridos ha continuado siendo básico en la enfermería moderna ${ }^{81}$.

Y creo que todo esto guarda relación con el concepto tan acendrado de "limpieza" que tenemos las enfermeras yen el que podemos profundizar de manera por cierto muy agradable, con la obra "Lo limpio y lo sucio"23.

Como es absolutamente visible, la influencia extranjera ha sido permanente desde la época de la conquista española.

$Y$ de tal manera, las herencias recibidas por tradición, continúan teniendo influencia a través de todas las épocas, incluyendo el Siglo XX. Sin embargo, se van desdibujando debido a la influencia del desarrollo socioeconómico, político y cultural, que ha ido transformando nuestro país, y especialmente, a partir de la década del 50 en que a medida que va creciendo el número de egresadas de las escuelas de enfermería, el ejercicio de la profesión va pasando de congregaciones religiosas a manos laicas, en un fenómeno que podríamos llamar de "Laicización" o "secularización de la enfermería", a la par que la influencia religiosa ha ido paulatinamente perdiendo fuerza; y la hegemonía de la Iglesia Católica acaba de romperse en la Constitución de 1991.

Por su parte, la situación de la mujer ha ido cambiando de manera definitiva, llegando a hacer decir a algunos, que si en éste país, ha habido alguna revolución en ese siglo, ésta ha sido la revolución femenina.

De la misma manera se van perdiendo las expresiones mas visibles de la influencia militar, que se advierten en el uso "no compulsivo" del uniforme yen el cambio de éste hacia estilos menos jerarquizantes y más asimilados a la ropa de calle.

También se advierte el cambio en la forma mas familiar de llamarse, en la desaparición de ciertos niveles intermedios de "supervisión", yen otros aspectos relacionados con la desaparición de las escuelas "anexas" a hospitales y de los internados.

La influencia antropológica o étnica, por el contrario, parece ser que se hace mas evidente, con la aceptación cada vez mayor de nuevas alternativas de "medicina", la entronización de prácticas naturistas, que las enfermeras dentro de su concepción de atención integral de salud al ser humano, cada día incorporan mas a su ejercicio profesional, y al cuidado de su propia salud ${ }^{5}$.

\section{Reflexiones finales}

La influencia española, como todas las influencias extranjeras, no se da en abstracto. 
Se introduce a través de las personas y de la ideología en la cual ellas están inmersas.

Por ello la influencia española en la enfermería colombiana es, ante todo, una influencia de los valores religiosos de aquellas personas que llegaron a Colombia en calidad de Enfermeros, los Hermanos Hospitalarios de San Juan de Dios y las Hermanas de la Presentación.

En el Nuevo Mundo, los .dos conceptos reflejados en los respectivos cargos: el de Enfermero Mayor (Jefe de Sala) y el de Servidor (quien da el servicio, atiende, cuida), son ocupados: el primero por los religiosos, o en su ausencia por una "distinguida dama de la alta sociedad", y el segundo, por "sirvientas" dirigidas por aquella.

Sin embargo, es interesante observar aquí como el cuidado de los hombres es asignado a los frailes y el cuidado de las mujeres a sirvientas dirigidas por una señora, mas o menos, como desde 1417 se reglamentara en España.

Esto se reflejaría mas adelante en la asimilación de la Religiosa Jefe de Sala, a una Economía, preocupada por el cuidado de "las cosas", más que por la dirección del cuidado de los enfermos; cuya atención directa es dejada a las Ayudantes de Enfermería (empíricas) y posteriormente a personal auxiliar, adestrado para tal fin por las mismas enfermera".

La influencia "científica" o talvez mejor sea dicho, la influencia "Médica" en últimas es francesa, ya que eran las concepciones de la medicina francesa las que por esa época campeaban en Europa. Además porque en 1827, luego de la creación por el General Santander en 1826 de la Universidad Grancolombiana con sus tres grandes centros: La Universidad Central de Venezuela, la Universidad Central del Ecuador y la Universidad Central de Colombia (cerrada esta ultima por José Hilario López en 1850 como efecto de la liberalización de la enseñanza y práctica de las profesiones, para reabrirse luego en 1867 por Santos Acosta como Universidad Nacional de los Estados Unidos de Colombia); aquel trae a Colombia dos profesores franceses, con lo cual se entroniza oficialmente la medicina francesa en el país.

Posteriormente, se hace lo mismo para enfermería, con la solicitud de Hermanas de la Presentación y la llegada de seis de ellas en 1873, para el Hospital de San Juan de Dios, el cual había sido adscrito a la Universidad Nacional des de su creación en 1867.

Como quien dice, que la enfermería colombiana desde sus cimientos en la era moderna de la profesión (que se inicia con Florence Nightingale en 1860), ha estado vinculada con la universidad y prueba de ello es el hecho de que la primera Escuela de Enfermeras se abrió en la Facultad de Medicina de la Universidad de Cartagena.

Por la ausencia de religiosos en los hospitales entre 1835 (año en que son expulsados los Hermanos Hospitalarios de San Juan de Dios) y 1873 (ano que llegan las Hermanas de la Presentación), la creación en ese lapso (1867) de la Universidad Nacional y la adscripción del Hospital de San Juan de Dios a su Facultad de Medicina, se establece una injerencia muy fuerte de los médicos en las labores de enfermería, quebando "la enfermería a cargo de los profesores de la Clínica". 
La influencia francesa en la enfermería colombiana se empieza a perder, unida a la "compra" del Canal de Panamá por los Estados Unidos y el establecimiento en la Zona del Canal de un Hospital de la mas alta tecnología (como se acostumbra cuando se trata de atender a militares), con su correspondiente Escuela de Enfermeras, llamada también, de manera significativa Santo Tomás.

Por la cercanía geográfica y cultural entre Cartagena y Panamá (antes de la venta del Canal ésta división político-administrativa se denominaba de "Cartagena e Istmo"), que hacía que las señoras de la alta burguesía cartagenera fueran a tener sus hijos a Panamá; las primeras directoras de la reorganizada Escuela de Enfermeras y Parteras de la Universidad de Cartagena a fines de la década de los 20's, fueron panameñas y es el pensum de ésta Escuela donde por primera vez en el país se introduce la materia de: Organización Hospitalaria y Administración, que corresponde a la necesidad de dirigir salas, organizadas ya por especialidades médicas, y no por sexo y edad (hombres, mujeres y niños) como en la escuela francesa.

Esta influencia americana se continúa a través de la creciente intervención de organismos internacionales como la Fundación Rockefeller, el Servicio Cooperativo Interamericano de Salud Pública, la Fundación Kellogg, la Oficina Sanitaria Panamericana con sede en Washington, etc.

Se acentúa con la implementación en el país del sistema americano de formación de enfermeras, traído por las primeras enfermeras colombianas que van a obtener la Licenciatura (Bachiller) y el postgrado (Magíster) a los Estados Unidos en la Universidad Católica; y la paulatina transformación de las Escuelas de Enfermeras adscritas a Hospitales, en Facultades de Enfermería dentro del sistema universitario, también con mucha influencia americana desde mediados de siglo.

Esta influencia francesa se rompe de manera decisiva con la salida de las Hermanas de la Presentación de las Escuelas de Enfermería, a medida que éstas van entrando a formar parte del sistema universitario y más tarde de los Hospitales, cuando las enfermeras seglares van asumiendo los recién creados Departamentos de Enfermería y el número de religiosas asignadas a éstas instituciones va diminuyendo.

Four statements inferenced from: religious traditions, gender or woman status, military heritage and ethnic inheritance, and their influence in nursing, are presented in this article. The ethnic inheritance analyses the issue based upon the cultural influences of the native -indigenous groups and the Spanish and Mediterranean attributes in nursing development.

The religious tradition began with Pedro Claver's J.C. presence between 1610 and 1617. His presence is followed by the "Hermanos Hospilalarios de San Juan de Dios" in 1768, and further with the presence of the sisters of Charity in 1873.

Lastly, the article compares the Barcelona's Santa Cruz hospital organization, where at that time, seems 
to appear a new type of nursing arrangement; which present functions and charges, currently utilized in Colombian hospitals (administrator of patient rooms, "Servidor", women in charge of female patients and sick children, "economa", chief in charge, and senior male nurse).

\section{REFERÊNCIAS BIBLIOGRÁFICAS}

01. ACOFAEN. Boletín Informativo. Año 5, n. 1, Agosto 1992.

02. ALATORRE WYNTER, Edda. Atención a la salud en la sociedad novo hispana. Rev. Enfermería Inst. Seguro Social, México, v. 3, n. 2/3, p. 75-7, 1990.

03. ALVÁREZ, Beatriz. O. P. Hermanas de la caridad dominicas de la presentación de la Santísima Virgen. Los diez primeros años de su implantación en Colombia. Salamanca, 1988 /Separata de Archivo Dominicano/ .

04. AVILA, Roselia et al. Enfermería: cadena o camino? México: Circulo de Estudios de Enfermería, 1986.

05. CAPRA, Fritjof. El punto crucial. Barcelona: Integral, 1987.

06. CASTRILLÓN A., MARIA CONSUELO Y CORREA, Alba Elena. La formación universitaria enfermeras. Colombia 1937 - 1980. Medellín. Tesis (Grado) Facultad de Educación Universidad de Antioquia, 1985.

07. DE LA PAZ, Angelina. O. P. Historia de la enfermería en Colombia. Medellín. Tesis (Grado) Facultad de Enfermería de la Universidad de Antioquia, 1963.

08. DOLAN, Josephine. Goodnow's history or nursing. México: Ed. Interamericana, [s.d.].

09. ESEVERRY, Cecilio. Historia de la enfermería española e iberoamericana. Barcelona: Salvat, 1984.

10. FRANK, Sister Charles Marie, ELIZONDO, Sor Teresa. Desarrollo histórico de la enfermería. México: Prensa Médica Mexicana, 1961.

11. FORERO CABALLERO, Hernando. Evolución histórica de la medicina en Santafé de Bogotá. Bogotá: Biblioteca de Autores Cundinamarqueses, 1983. Tomo 1. 
12. GAITÁN, María Cecilia. Aportes de las comunidades religiosas a la enfermería en Colombia. Rev. ANEC, Bogotá, Año V, v. 5, n. 13, p. 19-24, 1974.

13. GUTIERREZ DE PINEDA, Virginia. El triple legado. Bogotá: Universidad Nacional de Colombia, 1985.

14. LOZANO BAUTISTA, Guillermo. Beneficencia y Medicina. El Hospital de San Juan de Dios y la Universidad Nacional de Colombia. Bogotá: Fondo Editorial CIEC, 1983.

15. MARTÍNEZ BENITEZ, María Matilde et al. Sociología de una profesión. El caso de enfermería. México: Ediciones Nuevomar, 1985.

16. MARTíNEZ ZULAICA, Antonio. La medicina del siglo XVIII en el Nuevo Reino de Granada. Tunja: Edit. La Rana y el Águila, 1972.

17. RESTREPO Ch., GUILLERMO Y VILLA V., Agustín. Desarrollo de la salud pública Colombiana. Medellín: Universidad de Antioquia, 1980.

18. SORIANO LLERAS, Andrés. La Medicina en el Nuevo Reino de Granada durante la conquista y la colonia. 2. ed. Bogotá: Universidad Nacional de Colombia, 1972.

19. VELANDIA, Ana Luisa. Sistemas de salud dentro de diferentes formas de organización socioeconómica de las sociedades. Avances Enfermería, Bogotá, v. 1, n. 1, Jul-Dic. 1976.

20. VELANDIA, Ana Luisa. Desarrollo histórico de las instituciones que dan salud en el país. Rev. Perspectiva, Tunja, v. 3, n. 2, p. 8-20, 1986.

21. VELANDIA, Ana Luisa. La enfermería en Colombia: análisis socio histórico. Santafé de Bogotá: Universidad Nacional de Colombia, 1992. cap. 1: esquema conceptual.

22. VELANDIA, Ana Luisa. La Enfermería en Colombia: análisis socio histórico. Santafé de Bogotá: cap. 4: herencias recibidas por traducción.

23. VIGARELLO, Georges. Lo limpio y lo sucio. Madrid: Alianza Editorial, 1991.

24. ZABALETA JASPE, Horacio. Requimn por un viejo hospital. Bogotá: Tercer Mundo, 1976. 